\title{
Mobile Visualisation for On-Site Collaboration
}

\author{
O.Koseoglu ${ }^{1}$, D. Bouchlaghem ${ }^{2}$ \\ ${ }^{1}$ Laing O’Rourke, Integrated Solutions Dartford, UK \\ ${ }^{2}$ Loughborough University, Leicestershire, UK
}

\begin{abstract}
There are various parties involved in construction projects. This multi-disciplinary environment makes it difficult to work collaboratively especially during design problem resolution and decision making on site. Better collaboration between design teams and construction sites may enable the construction industry to deliver projects on time and within budget. The latest mobile and visualisation technologies can support mobile visualisation applications and collaboration between distributed construction site and design teams. These applications and collaboration may improve the distribution and clarification of drawings, management of design changes, resolution of buildability problems, and the monitoring of construction progress, all in real time.
\end{abstract}

The paper provides an overview of design information communication and collaboration between the construction site and design teams. It then highlights the key results of a questionnaire survey on the needs \& requirements from the construction industry and presents the implementation of mobile visualisation in construction. Further, the paper describes the results of the validation of scenarios illustrating the planning and implementation of mobile communication and visualisation technologies to support design teams and the construction site.

Keywords-collaboration,

construction,

mobile, visualisation.

\section{INTRODUCTION}

The communication process and real-time transfer of information and knowledge are key areas for effective coordination and collaboration within construction projects $[1,2]$. Communication and collaboration between project members during the construction process should be carefully planned to enable better decision making [3]. This is important for both the design and construction stages of the project. The prominent medium through which designers convey their intentions to contractors is through drawings and specifications [1]. After the drawings and design specifications are complete, the need for change still remains. The situation may arise where there is a need for clarification on drawings and specifications [4]. Therefore, the design and the construction process suffers if there is not an easy and efficient exchange of information between the drawing office and construction site [5]. When design drawings and specifications arrive on site, valuable time and manpower are usually wasted searching for the appropriate ones. Traditional 2D paper-based drawings are not always adequate in giving a sense of the dynamic process of construction as they do not show the order of assembly [6]. Visualisation tools are playing an important role for design collaboration through various technologies such as 3D and 4D modeling. The benefits of 3D modeling can be felt through the project lifecycle but had limited use so far [7]. In a 3D model project members can visualize images of construction, share project information and review constructability issues [8]. However, 3D does not enable supply chain members to monitor progress of construction projects [9]. 4D CAD models enable project teams to explore various 'what-if' scenarios and identify conflicts. Moreover, communicating scheduling details and 3D models to the whole supply chain is one of the important aspects of 4D modeling $[10,11]$. By using 4D models in real-time, there will be two way communications between construction site engineers and other project members. This enables the design office, head office, etc. to monitor how work is progressing, what problems have occurred, what information is needed, which materials and equipment are required etc. [12].

Collaboration is a very important aspect of construction projects, many contractors nowadays use IT based project collaboration technologies [13]. On the other hand, collaborative technologies are not limited to collaboration software and document management platforms for collecting, storing and retrieving design information. Mobile computing and wireless networking have experienced rapid developments over the last decade, with many industrial sectors realizing the benefits of mobile collaboration. Communication and collaboration in construction will move to a new dimension with the use of mobile technologies which can enable remote information access to and from offices and sites [14]. Construction professionals are becoming aware of the benefits of implementation of mobile technologies on their work activities. On the other hand, most of them experience difficulties when implementing these technologies on projects [15]. Some construction collaboration technology providers and end-users have already tested the use of mobile devices on site [13]. However, most trials focused on asynchronous use where the data is not exchanged in real time [13]. Remote access to architectural drawings and specifications is an essential need for mobile construction workers. There is a need to improve communication between designers and builders and the use of mobile technologies may contribute to this [16]. Moreover, wireless communications enable site engineers to transmit digital photos and videos to project members in order to monitor progress and to allow a speedy review of problems on site [16].

Visualisation through mobile technologies is an important research topic. Due to the limitation in computational resources of mobile devices, the visualisation of design documents has not been investigated in detail. Therefore, there is not much research reported in the literature about mobile visualisation of design documents in construction or any 
other industry. However, the integration of mobile devices into the visual representation of design documents and specifications may offer new opportunities for accessing and monitoring the construction remotely. The main aim of this research is to investigate the use of mobile communication between design teams and construction jobsites with a focus of achieving real-time collaboration between the various parties involved in design problem resolution.

\section{QUESTIONNAIRE SURVEY}

An industrial survey was carried out to review the perspective of mobile and visualisation technologies in construction and to gather information on collaborative working practices during the construction stage of the project lifecycle. The main aim of the survey was to investigate collaboration practices between design and construction teams using mobile and visualisation technologies. The questionnaire was composed of 4 different sections including 15 questions in total. The sections are: Personal details and organizational information, wireless and mobile technologies in construction, visualisation in construction and designconstruction collaboration on site. The questionnaire was developed using the online survey software 'QuestionPro`. It is composed of an interface for creating and structuring questions, and tools for analyzing and viewing results. All of the questions were closed the type to save time and make it easier for respondents to complete. The questionnaire was first prepared and then transferred into the software to finalize and distribute through e-mails. Several pilots were conducted during the development of survey to ensure clarity and completeness of questions. During these pilots, the length of the questionnaire was shortened and some of the questions were rewritten to improve clarity. In this survey, the sampling frame was composed of professionals having different backgrounds, positions and roles in the construction industry. They were short listed and selected according to their areas of interest and expertise from a database storing contacts of previous research projects carried out in Civil \& Building Engineering Department, Loughborough University. Out of the 179 respondents, 54 of these viewed the questionnaire and 34 of them completed it. The overall response rate is $21 \%$ and average time taken to complete survey was 13 minutes. The results were used to identify key issues for the planning and implementation of effective designconstruction collaboration through mobile and visualisation technologies.

Information on respondent's profiles and organizations involved in the survey can be summarized as follows:

- $82 \%$ of the respondents had been involved in their field for more than 10 years and $47 \%$ of them have more than 20 years experience.

- $70 \%$ of respondents are working for organizations in the UK, others are from the United States, the Netherlands, Sweden, France, Portugal, Turkey and Singapore.

- Business areas of the organizations in which respondents are working cover a wide variety of disciplines involved in construction practices.
Respondents were asked questions aimed at investigating the use of wireless and mobile technologies on construction projects. Fig. 1, 2, and 3 below illustrate the use of wireless technologies and mobile devices; as well as the areas of use of these technologies in construction projects.

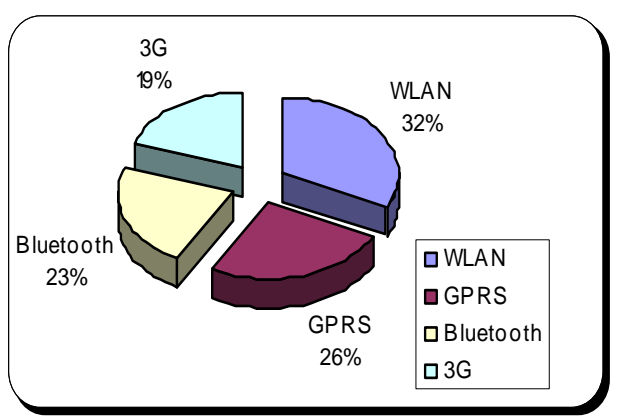

Figure 1. Use of wireless technologies

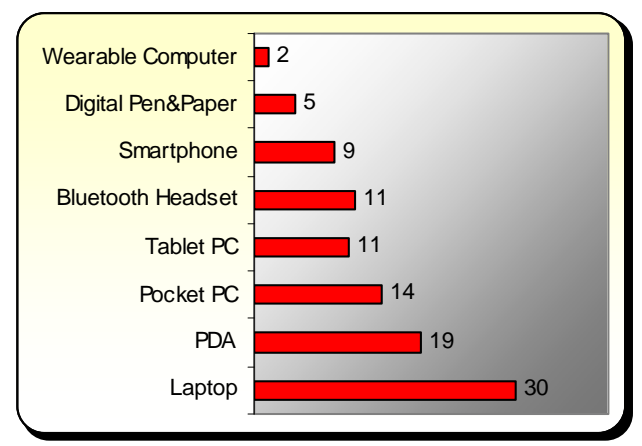

Figure 2. Use of mobile devices (\%)

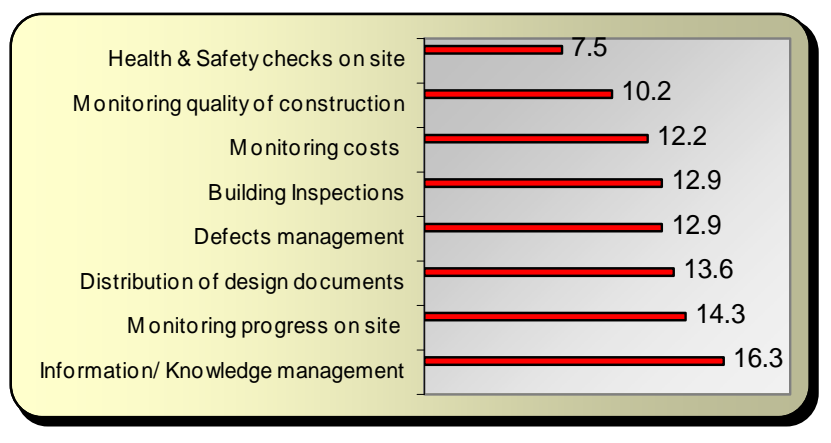

Figure 3. Activity distributions for use of mobile and wireless technologies (\%)

Next the respondents were asked to indicate the frequency of use of visualization technologies (see Fig.4) and the stages where they are used in a typical construction project (see Fig.5, 6, and 7). The latter were identified as: Client briefing, feasibility, conceptual design, detailed design, project planning, construction, marketing, and facilities management. 


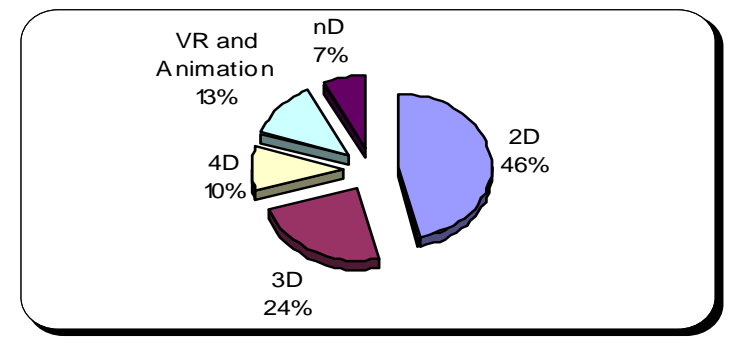

Figure 4. The use of visualization technologies on construction projects

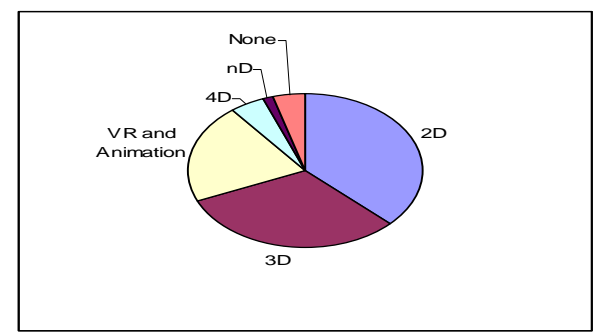

Figure 5. Client Briefing

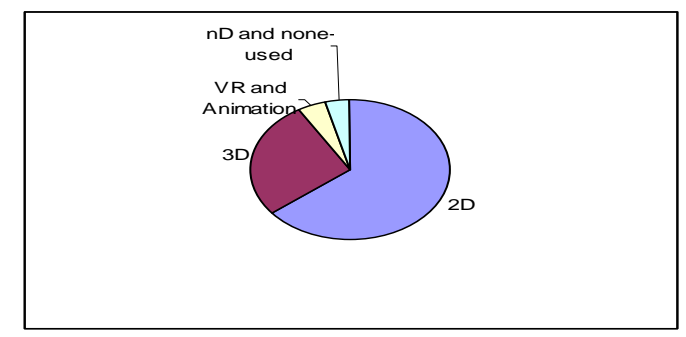

Figure 6. Detailed Design

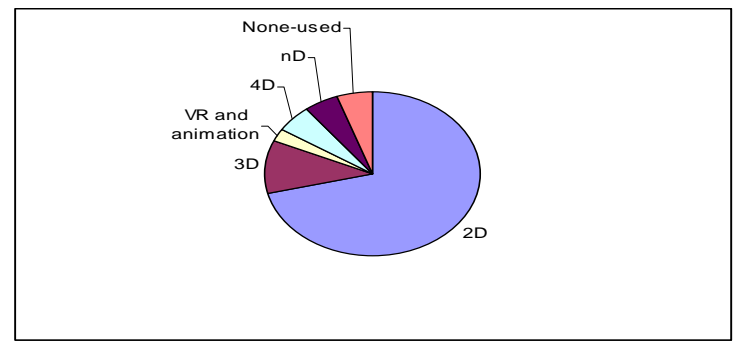

Figure 7. Construction stage

In the next part of the survey, respondents were asked questions about design/construction collaboration on site. Most of them were related to design changes made to a project during construction and collaboration tools used between project workers for the resolution of design problems. Respondents were asked to indicate the frequency of occurrences and causes of design changes in construction projects ( Fig.8 and 9).

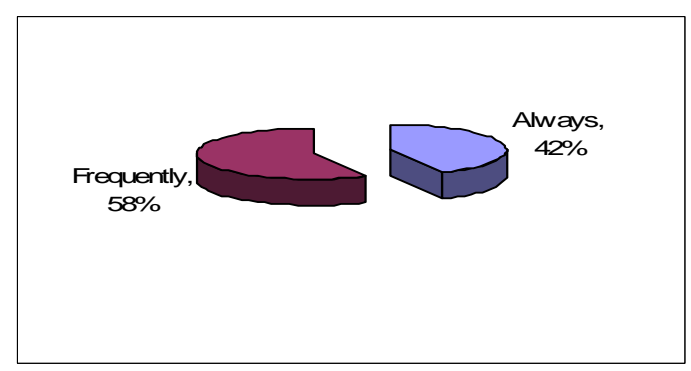

Figure 8. Frequency of design changes

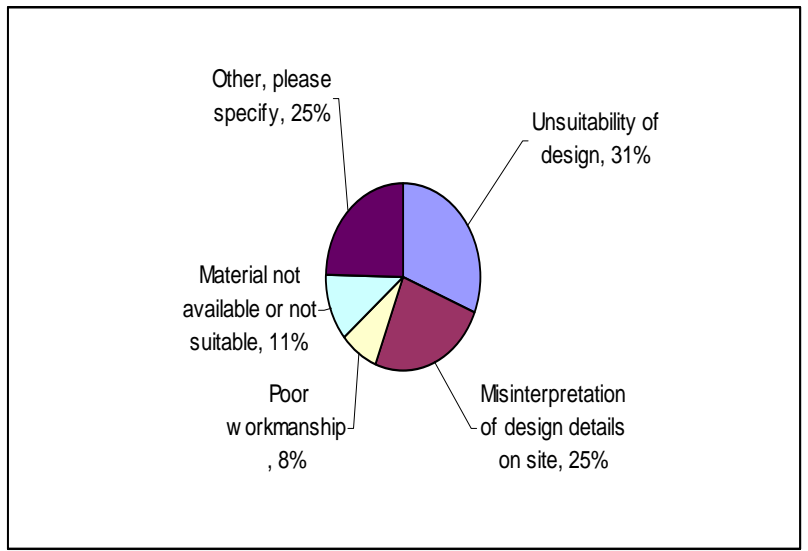

Figure 9. Main causes of design changes

Respondents were also asked to identify how long it takes to update drawings once a design rework has been identified on site (Fig.10).

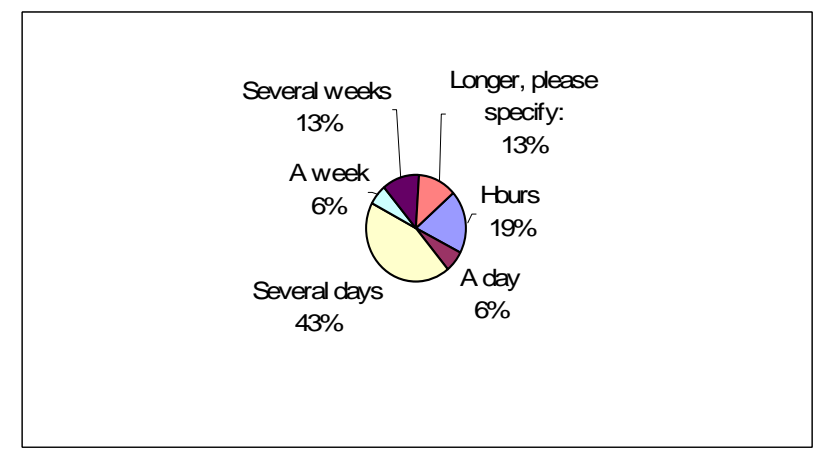

Figure 10. Time for updating drawings due to design rework on site

The use of different communication and collaboration tools and methods during the resolution of design problems on site were the focus of the next set of questions. The results (Fig.11) revealed that 67\% of respondents use traditional communication methods and tools to resolve design problems. The main methods and tools include: face-to-face meeting, telephone, fax and mail/courier, teleconferencing while $33 \%$ of respondents use computer and internet based technologies such as email, extranet, visualisation and videoconferencing.

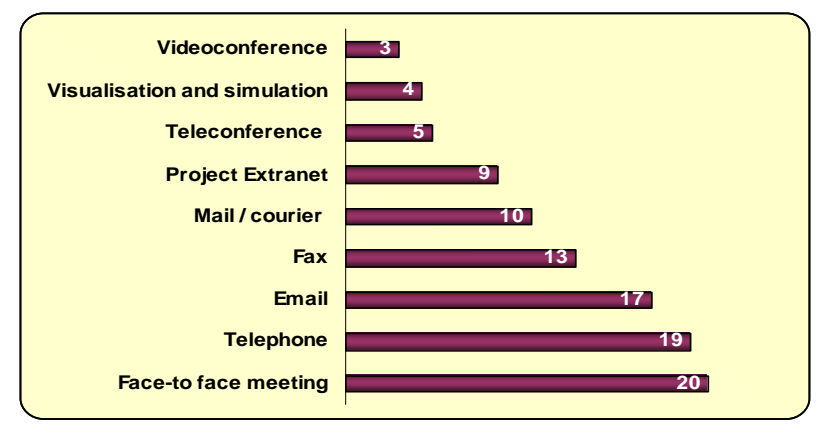

Figure 11. Use of communication and collaboration methods to resolve design problems on site ( \%)

The key results of the survey are summarised as follows:

- Wireless \& mobile technologies are being used by construction industry organizations to support collaboration for various activities. However, they 
have not become common collaborative tools on construction sites. Therefore there should be a structured framework to implement these technologies within the construction site processes.

- The three most important needs of a mobile project worker on site are accessing information/knowledge, design documents/ specifications, and real-time monitoring of progress on site.

- Visualisation can play a key role in the communication of project design information between construction and design teams. Technologies such as $3 \mathrm{D}, 4 \mathrm{D}, \mathrm{nD}$ modelling and VR are used in different stages of construction projects. However, during the construction stage most professionals prefer to use 2D drawings while the use of other visualisation technologies is still limited. This makes the handling of design problems difficult on construction sites.

- Design changes occur frequently in construction projects. The main reason for these changes are design related. Therefore, the best way to alleviate the effects of these changes on the project cost and time is to establish a new integrated collaboration model and collaborative working environment between design and construction teams.

\section{Planning \& Implementation of Mobile VISUALISATION}

The planning and implementation mobile visualisation in construction within this research highlights the need for the use of various mobile technologies and wireless communications, collaboration software, and visualisation applications to create a better collaboration environment. This will result in a new collaboration model integrating these technologies and could potentially improve collaboration platforms and tools used to deal with design specific issues on construction sites.

The objectives for the planning \& implementation are:

- To provide a real-time wireless communication platform capable of using collaboration software, visualisation technologies and communication tools to support collaboration between engineers on site and other project members.

- To provide a real-time and mobile telecommunication based platform capable of sharing visual information to support communication and knowledge sharing between engineers on site and other project members.

- To demonstrate how mobile visualisation can enhance the existing design problem resolution and decision making processes during the construction stage of a project.

- To evaluate the use of these technologies within various organizations and identify technical and nontechnical issues which occur during the implementation on real construction projects.

\section{A. Implementation Scenarios}

In recent years people's interest has moved from developing scenarios to successfully using them, scenario planning success depends on capability of looking at the future in the future's conditions [17]. The scenario planning method was used in this research after reviewing the literature and identifying the needs of construction industry through the questionnaire survey. Scenario validation meetings were held with experts from different organizations in the construction industry. The aim was to ensure that the scenarios generated within this research are appropriate within the construction environment.

This research presents three different scenarios, illustrating the use of technologies for communication and collaboration between the construction jobsite and design teams. These are: Mobile 2D/3D, 4D Collaboration, and 3G Communication. These scenarios include various mobile devices, wireless networks and visualisation technologies. Figure 12 presents the key technologies underlying the scenarios and mobile communication architecture for data, audio and visual information transfer through wireless technologies. Scenario generation and the architecture of wireless networks based on literature review and technology review; and the needs of the construction industry identified through the questionnaire survey.

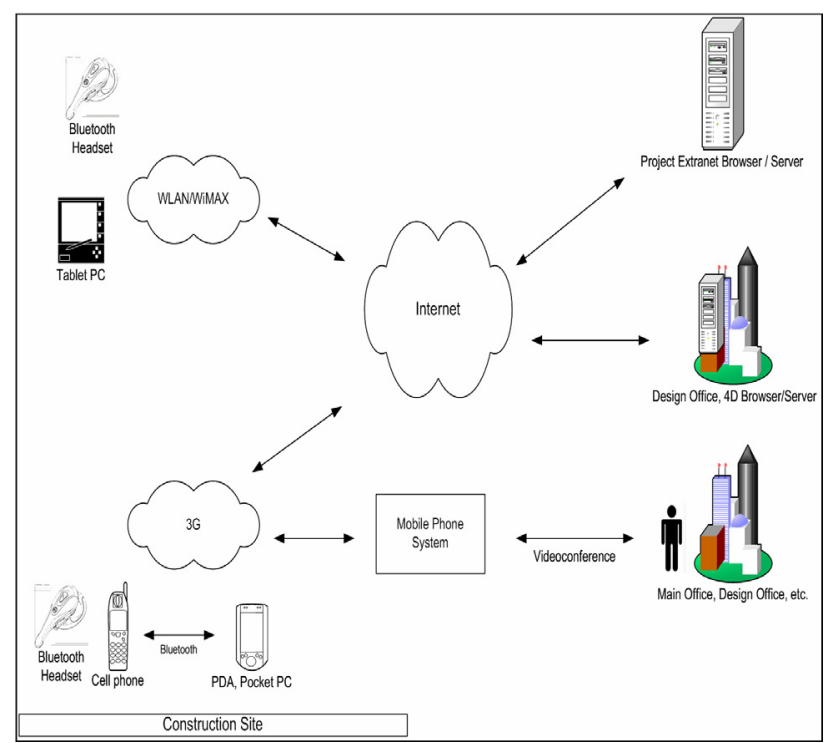

Figure 12. Mobile communication architecture for data, audio and visual information transfer through wireless technologies and general technology layout of implementation scenarios

Table 1 explains the proposed technologies for each scenario together with their benefits and drawbacks; this was used as a guide for the technology set up within the scenarios explained in the following sections. 
TABLE I.

TECHNOLOGIES PROPOSED FOR USE IN THE SCENARIOS

\begin{tabular}{|c|c|c|c|}
\hline Technology & $\begin{array}{c}\text { Scenario \& Process } \\
\text { Identified }\end{array}$ & Benefits & Drawbacks \\
\hline Tablet PC (Device) & $\begin{array}{l}\text { Mobile 2D/3D (accessing } \\
\text { published drawings, } \\
\text { documents and specifications). } \\
\text { 4D Collaboration (monitoring } \\
\text { progress on site). }\end{array}$ & $\begin{array}{l}\text { Similar to a small laptop, } \\
\text { lightweight design holds like a } \\
\text { book and can be used sitting or } \\
\text { standing. } \\
\text { Suitable for viewing large format } \\
\text { information such as published } \\
\text { 2D/3D drawings. } \\
\text { Long battery life provides using in } \\
\text { different environments for long } \\
\text { time. } \\
\text { No barrier between the user and the } \\
\text { others, information can easily be } \\
\text { shared with the person nearby. } \\
\text { User can use own handwriting on } \\
\text { the screen. This leads to drawing } \\
\text { figures, sketching and using the PC } \\
\text { as a worksheet. } \\
\text { Gives the user freedom of } \\
\text { movement. } \\
\text { Most have integrated Bluetooth and } \\
\text { WLAN technology in order to be } \\
\text { used in wireless networks. }\end{array}$ & $\begin{array}{l}\text { It requires two hands to operate due } \\
\text { to larger form compared to small } \\
\text { devices. } \\
\text { Rugged ones have to be used at } \\
\text { construction sites due to harsh } \\
\text { working environments, these are } \\
\text { more expensive than normal Tablet } \\
\text { PCs. }\end{array}$ \\
\hline Pocket PC (Device) & $\begin{array}{l}\text { 3G Communication } \\
\text { (instantaneous decision } \\
\text { making, sharing visual } \\
\text { information and knowledge) }\end{array}$ & $\begin{array}{l}\text { Pocket PCs have large and clear } \\
\text { full-color screens compared to } \\
\text { Personal Digital Assistants (PDAs). } \\
\text { Manufacturers produce devices } \\
\text { which have Bluetooth technology, } \\
\text { WLAN and 3G technology. } \\
\text { Enables capturing videos and } \\
\text { photos related to construction on } \\
\text { site. } \\
\text { Real-time videoconference with } \\
\text { project team members using } 3 G \\
\text { networks. }\end{array}$ & $\begin{array}{l}\text { It is unsuitable for viewing large } \\
\text { format information such as } \\
\text { drawings. }\end{array}$ \\
\hline $\begin{array}{l}\text { 3G Mobile Phone } \\
\text { (Device) }\end{array}$ & $\begin{array}{l}\text { 3G Communication } \\
\text { (instantaneous decision } \\
\text { making, sharing visual } \\
\text { information and knowledge) }\end{array}$ & $\begin{array}{l}\text { Enables capturing videos and } \\
\text { photos related to construction on } \\
\text { site. Real-time videoconference } \\
\text { with project team. }\end{array}$ & Limited screen size \\
\hline Bluetooth Headset & $\begin{array}{l}\text { Mobile 2D/3D (accessing } \\
\text { published drawings, } \\
\text { documents and specifications). } \\
\text { 4D Collaboration (monitoring } \\
\text { progress on site). } \\
\text { 3G Communication } \\
\text { (instantaneous decision } \\
\text { making, sharing visual } \\
\text { information and knowledge) }\end{array}$ & $\begin{array}{l}\text { Hands free voice calls through } \\
\text { VoIP (Voice over Internet } \\
\text { Protocol) by accessing to Bluetooth } \\
\text { enabled mobile devices. } \\
\text { Easy set up and efficient use for } \\
\text { mobile workers on site. }\end{array}$ & $\begin{array}{l}\text { Needs to be protected from harsh } \\
\text { outdoor environments. }\end{array}$ \\
\hline $\begin{array}{l}\text { WLAN (Wireless Local Area } \\
\text { Network) }\end{array}$ & $\begin{array}{l}\text { Mobile 2D/3D (accessing } \\
\text { published drawings, } \\
\text { documents and specifications). } \\
\text { 4D Collaboration (monitoring } \\
\text { progress on site). }\end{array}$ & $\begin{array}{l}\text { There is no additional data transfer } \\
\text { cost apart from installation and } \\
\text { hardware. } \\
\text { Enables transferring large files due } \\
\text { to having higher data transfer rates } \\
\text { than 3G. } \\
\text { Information can be downloaded } \\
\text { whenever required, limiting the } \\
\text { need for device memory. }\end{array}$ & $\begin{array}{l}\text { Requires installation of WLAN } \\
\text { access points and antennas (limited } \\
\text { coverage). } \\
\text { Construction site requires outdoor } \\
\text { hardware components which are } \\
\text { more expensive than indoor WLAN } \\
\text { equipment. }\end{array}$ \\
\hline
\end{tabular}




\begin{tabular}{|c|c|c|c|}
\hline $\begin{array}{l}\text { WiMAX (Worldwide } \\
\text { Interoperability for Microwave } \\
\text { Access) }\end{array}$ & $\begin{array}{l}\text { Mobile 2D/3D (accessing } \\
\text { published drawings, } \\
\text { documents and specifications). } \\
\text { 4D Collaboration (monitoring } \\
\text { progress on site). }\end{array}$ & $\begin{array}{l}\text { Deliver broadband connectivity in } \\
\text { a larger geographic area than } \\
\text { WLAN and enable greater } \\
\text { mobility for high speed data } \\
\text { applications. } \\
\text { It has nearly cell radius of 4-6 } \\
\text { miles and range up to } 30 \text { miles }\end{array}$ & $\begin{array}{l}\text { Set up like mobile phone system by } \\
\text { using base stations that serve a } \\
\text { radius of several miles and it is } \\
\text { more expensive than WLANs. } \\
\text { The certification of WiMAX has } \\
\text { been delayed and unlicensed } \\
\text { network equipment are used by } \\
\text { network providers. } \\
\text { WiMAX compatible mobile devices } \\
\text { have not been produced yet. } \\
\text { There will be a regular service } \\
\text { provider fee apart from hardware } \\
\text { and installation costs. }\end{array}$ \\
\hline $\begin{array}{l}\text { 3G (Third Generation Mobile } \\
\text { Phone System) }\end{array}$ & $\begin{array}{l}\text { 3G Communication } \\
\text { (instantaneous decision } \\
\text { making, sharing visual } \\
\text { information and knowledge) }\end{array}$ & $\begin{array}{l}\text { Video on demand, video } \\
\text { conferencing, high speed } \\
\text { multimedia and mobile internet } \\
\text { access are the important features. } \\
\text { Data transfer rates are much faster } \\
\text { than the existing mobile } \\
\text { telecommunication networks. } \\
\text { Provides wide area coverage } \\
\text { compared to WLAN and WiMAX. }\end{array}$ & $\begin{array}{l}\text { 3G licenses have been awarded } \\
\text { around the world at huge costs by } \\
\text { many governments and operators } \\
\text { still offer expensive prices for high } \\
\text { rates of use. } \\
\text { Data transfer rate is not suitable for } \\
\text { downloading large files like models } \\
\text { and drawings. } \\
\text { Network coverage needs to be } \\
\text { expanded at remote sites. }\end{array}$ \\
\hline Bluetooth & $\begin{array}{l}\text { Mobile 2D/3D (accessing } \\
\text { published drawings, } \\
\text { documents and specifications). } \\
\text { 4D Collaboration (monitoring } \\
\text { progress on site). } \\
\text { 3G Communication } \\
\text { (instantaneous decision } \\
\text { making, sharing visual } \\
\text { information and knowledge) }\end{array}$ & $\begin{array}{l}\text { Provides fast and secure voice and } \\
\text { data communications. } \\
\text { Low-cost wireless network solution } \\
\text { Cable Replacement } \\
\text { Suitable for personal area } \\
\text { networking. }\end{array}$ & $\begin{array}{l}\text { Short range and the limited data } \\
\text { transmission rate. } \\
\text { Range is up to } 10 \text { meters and } \\
\text { theoretical data transfer rate is } \\
1 \text { Mbps }\end{array}$ \\
\hline $\begin{array}{l}\text { Project Extranet (Collaboration } \\
\text { Software) }\end{array}$ & $\begin{array}{l}\text { Mobile 2D/3D (accessing } \\
\text { published drawings, } \\
\text { documents and specifications). } \\
\text { 3G Communication } \\
\text { (instantaneous decision } \\
\text { making, sharing visual } \\
\text { information and knowledge) }\end{array}$ & $\begin{array}{l}\text { Real-time access to published } \\
\text { drawings and model files as 2D or } \\
\text { 3D; project documents; } \\
\text { specifications; etc. } \\
\text { Better drawing and document } \\
\text { circulation between project } \\
\text { members. } \\
\text { Provides storage space to visual } \\
\text { information such as videos and } \\
\text { photos captured from the } \\
\text { construction site for sharing within } \\
\text { project team. } \\
\text { Notify users through e-mails if any } \\
\text { change or mark-up raised during } \\
\text { the project. }\end{array}$ & $\begin{array}{l}\text { Slower rates of data transmission } \\
\text { due to poor web server. }\end{array}$ \\
\hline $\begin{array}{l}\text { Web-based 4D modeling } \\
\text { Software }\end{array}$ & $\begin{array}{l}\text { 4D Collaboration (monitoring } \\
\text { progress on site). }\end{array}$ & $\begin{array}{l}\text { Real-time access to updated } \\
\text { schedule and 3D model of the } \\
\text { construction. } \\
\text { Monitoring the resources, cost, etc. } \\
\text { during the actual construction } \\
\text { according to planned program. }\end{array}$ & $\begin{array}{l}\text { Technical problems during web- } \\
\text { based collaboration due to internet } \\
\text { infrastructure. }\end{array}$ \\
\hline
\end{tabular}




\section{1) Mobile $2 \mathrm{D} / 3 \mathrm{D}$ scenario}

This scenario illustrates the case of a site engineer who communicates and collaborates with the project team in real-time, accessing project drawings, documents and specifications, and requests information for design queries or buildability problems. Figure 13 shows a scenario based on the exchange and distribution of 2D/3D design documents between the project team members and the construction jobsite. The mobile $2 \mathrm{D} / 3 \mathrm{D}$ scenario is explained as follows:

- The engineer uses a rugged (suitable for outdoor and harsh environments), Bluetooth and WLAN enabled Tablet PC, and Bluetooth enabled headset. The Tablet PC and headset communicate with each other using the Bluetooth network.
- The construction site is covered with a wireless network (802.11g) using outdoor access points and antennas. It is likely in the future that operators may provide WiMAX internet access to subscribers without the need to install any antennas and access points.

- The engineer connects to the web using the wireless network and logs-in to the web server of the project extranet service provider.

- Audio communication between the project members is established through Skype, a free Voice Over Internet Protocol (VoIP) service provider on the web. Moreover, the engineer can call landlines and mobile phones all over the world for a cost that is cheaper than existing telephone networks. They can accept calls from landlines or mobile phones using their Skype account.

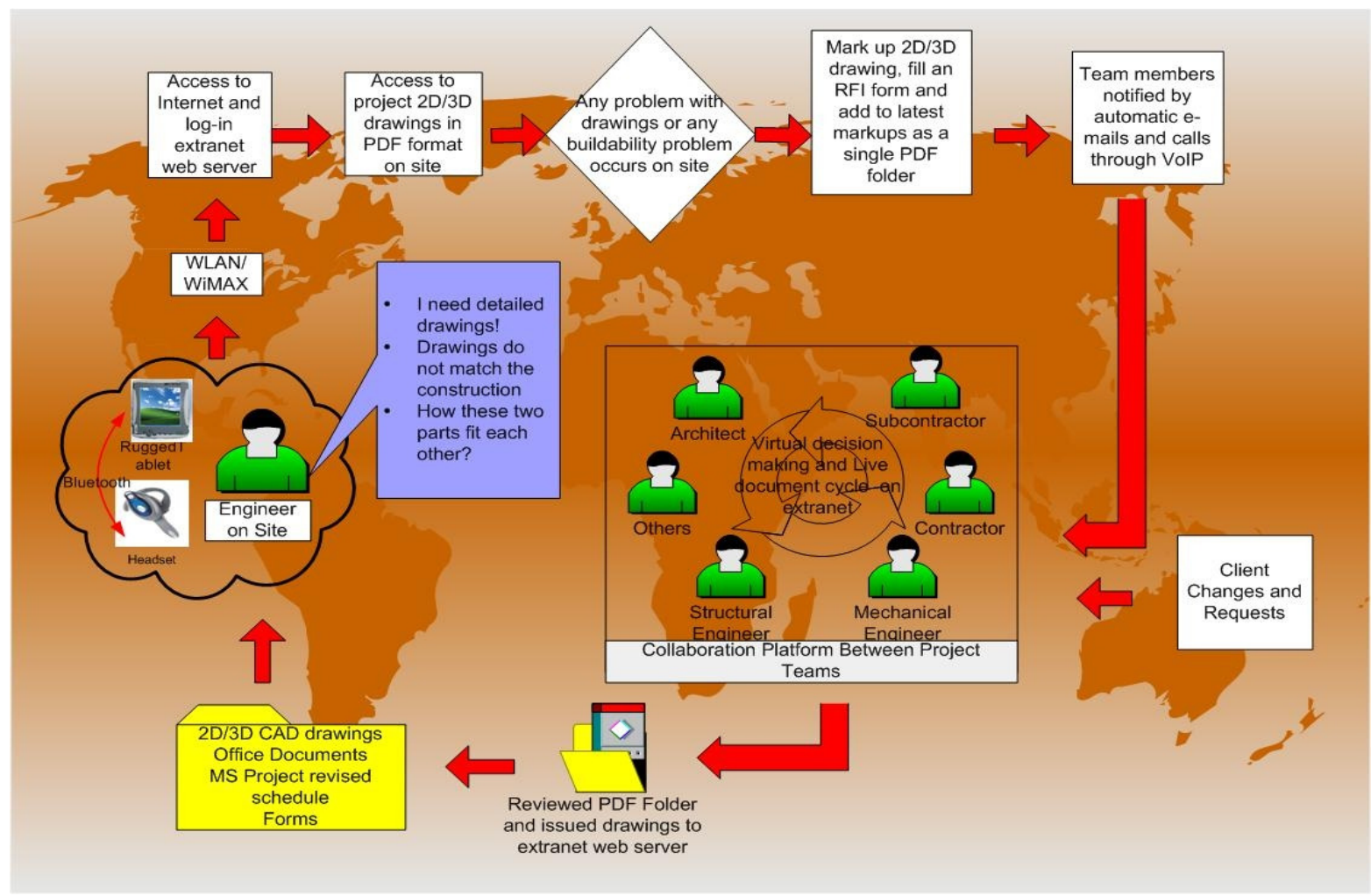

Figure 13. Mobile 2D/3D Scenario

- After connecting to the project extranet and Skype account, they can search for Online team members and display any required 2D/3D drawings, specifications, documents, etc. in Portable document format (PDF) through an extensive and advanced search on the server.

- Publishing the drawings into Adobe Acrobat Professional and Acrobat 3D enables the project team to read and comment on any drawing or MS office document without the need to access the CAD or project management software. Moreover, CAD files are produced from a variety of different parties who use different formats. These 2D/3D files can be easily converted to PDF, a standard format for sharing the CAD data.

- The site engineer can monitor the construction by displaying drawings and documents on Tablet PC screen. If there are any queries on drawings, the engineer can mark up the PDF file with their own handwriting using a pen-based Tablet PC and raise Request for Information (RFI) attaching it as "marks up” folder. The RFI can be an intelligent PDF folder which contains multiple files such as CAD, Office or MS Project documents, images, etc.

- Project team members are notified by e-mail when any document is uploaded to the collaborative environment. The site engineer has the option to notify relevant parties in the project team through the VoIP.

- Designers, client, contractor, subcontractors, etc. have a collaborative decision making and document exchange platform on the web. When any problem occurs on the construction site or the client requests a change in the design, a redesign takes place in realtime and is communicated back to the site engineer.

- Revised drawings, updated MS project schedules and even cost changes in an Excel file can be inserted into a single PDF folder and upload to the system. 
- All project team members are notified about the changes or revisions to the project documents and the revised files are distributed to the construction site user in real time.

\section{2) 4D Collaboration scenario}

This scenario illustrates the case of a site engineer who checks and monitors the progress of the construction against planned schedules, resources, specifications, etc. They access a collaborative 4D modeling platform and communicate with the project team using a 3D model which enables them to manage resources, schedule, tasksand cost, and explore various "what if" scenarios on the construction jobsite. Figure 14 presents the scenario which is explained as follows:

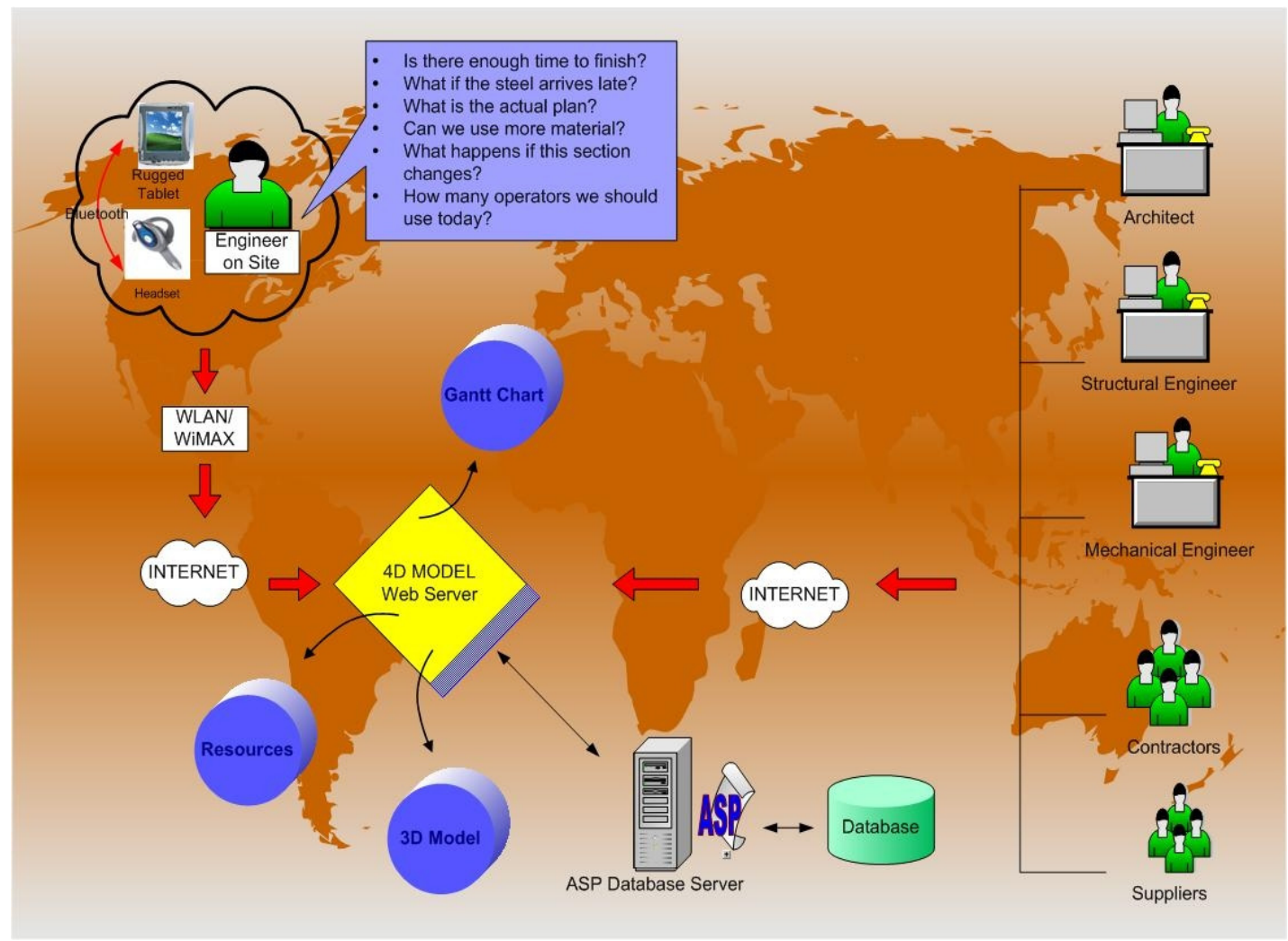

Figure 14. 4D Collaboration Scenario

- Similar to the previous scenario the engineer uses a rugged, Bluetooth and WLAN enabled Tablet PC, and Bluetooth enabled headset.

- Wireless communication is established either using outdoor access points and antennas or in the future operators may provide WiMAX internet access to subscribers without the need for installing any antennas and access points.

- The engineer connects to the web through the wireless network and accesses the 4D (3D+time) model server, where the audio communication between project members is established through Skype.

- The engineer displays the 3D (three dimensional) model of the building, Gantt chart and Resources (material, labor, equipment) on the screen of Tablet PC in real time with the project team. They can check and monitor the construction activities, schedule and resources using the 3D model. This makes it easier to understand the different steps of construction.

- Using a real-time and web based 4D modelling platform in a collaborative environment enables the project members to have an interactive visual representation of resources, changes in schedule, and design. The site engineer and project team can visualize different "what-if" scenarios when a buildability issue arises. This makes the decision making process more collaborative, faster and easier.

- Real-time updates on the project schedule and resources occur following the changes in design. This enables a better coordination with sub-contactors and suppliers. Feedback from the site engineer in the case of any problems which result in a change to the plans, drawings, specifications, materials, etc. makes it easier to solve issues quicker, and leads to better project coordination.

\section{3) $3 G$ Communication scenario}

This scenario illustrates the case of a site engineer who makes decisions and shares information and knowledge using $3 G$ visual communications to solve buildability problems on a construction site. Figure 15 presents the scenario and its details are explained below: 


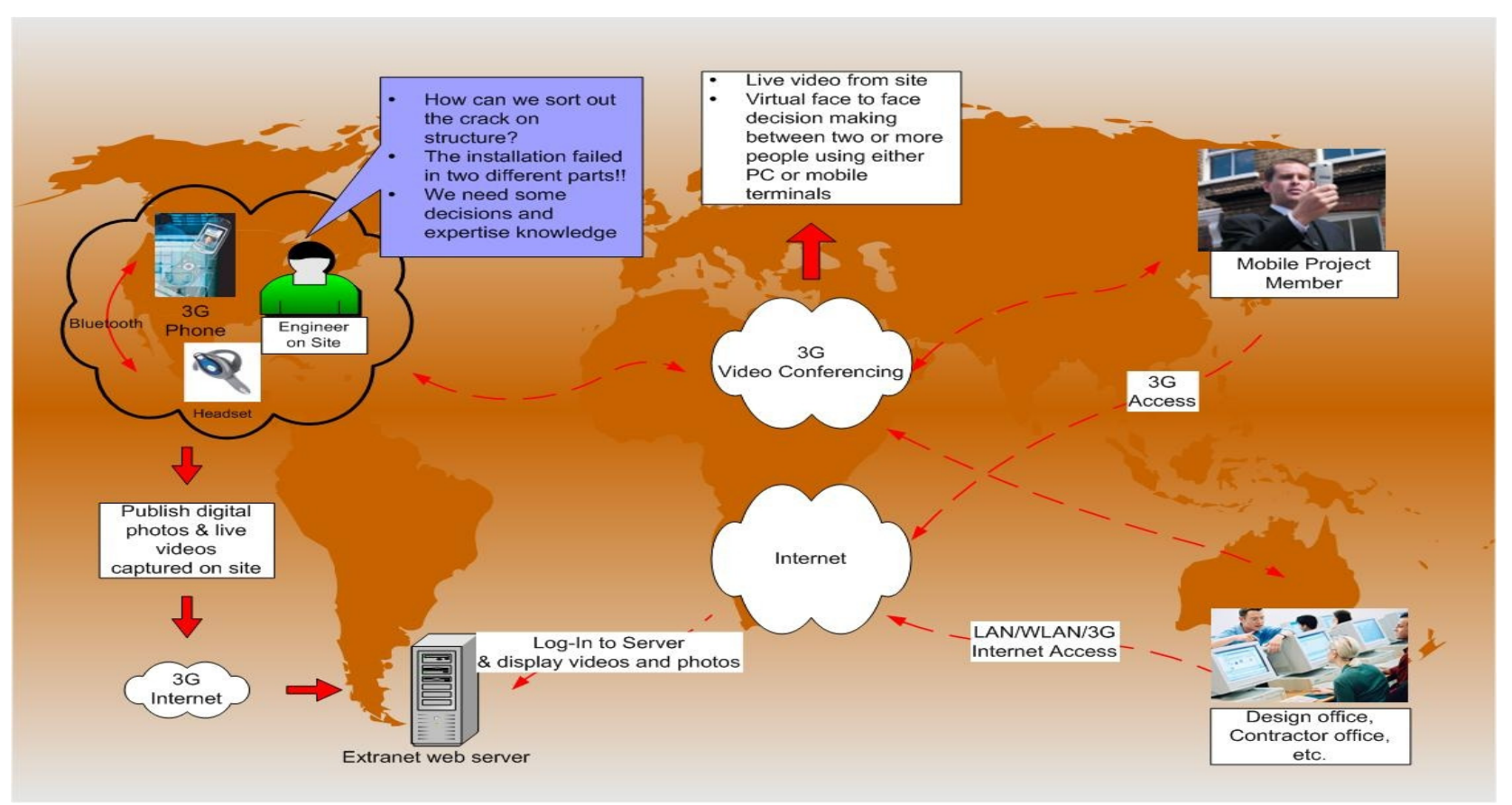

Figure 15. 3G Communication Scenario

- The engineer has a Bluetooth enabled 3G smart-phone and a Bluetooth headset which provides hands-free voice communication and isolates the sound coming from outside during a videoconference on a construction site.

- While the site engineer monitors the construction, there are likely to be buildability problems and unexpected conditions due to weather, soil conditions, failures of materials, etc. In these situations 3G provides the opportunity of sharing visual information, improvements in accessing tacit knowledge from experts and making collaborative real-time decisions using an interactive face-to-face platform with project members.

- The site engineer can capture digital photos and live videos from the construction site and using Internet access they can upload photos and live videos to the extranet web server or directly send them to a project team member.

- Apart from image distribution and live video delivery, the $3 G$ phone system allows users to make virtual face-to-face video phone calls. Due to the outdoor and harsh environments of construction sites, it is impossible to have real-time videoconference meetings in the same way as is done indoors. However, 3G provides anytime-anywhere face-to-face meetings, and site engineers can participate in a video conversation with both $3 \mathrm{G}$ mobile phone users and PC users who have $3 \mathrm{G}$ cards and video telephony software.

\section{B. Scenario validation}

Experts for the scenario validation were short listed from the respondents of the industrial survey. They were selected according to their backgrounds, years of experience, and organizations. The main aim for scenario validation meetings was to find out possible drivers/barriers which may occur during the implementation of these scenarios, identify benefits/drawbacks, and investigate other possible applications and/or limitations of these scenarios. Another aim was to identify project data necessary for the implementation of these scenarios within the interviewees' organisations. Semi-structured interviews were held with eight experts in five different companies. The experts were based in design/engineering and contracting/management consultancies (Table 2). The scenarios were presented to the experts using PowerPoint slides; these were also distributed to experts prior to the meetings. The presentations included the aim of the research, a brief methodology, the key results of the survey, underlying technologies, and visual representations of the scenarios prepared using Visio.

TABLE II.

ORGANIZATION AND INTERVIEWEE PROFILES INVOLVED IN SCENARIO VALIDATION

\begin{tabular}{|l|l|l|}
\hline \multicolumn{1}{|c|}{ Organization } & \multicolumn{1}{|c|}{$\begin{array}{c}\text { Main role in } \\
\text { organization }\end{array}$} & \multicolumn{1}{c|}{$\begin{array}{c}\text { Experience } \\
\text { (years) }\end{array}$} \\
\hline Management consultancy & $\begin{array}{l}\text { Business and } \\
\text { Technology } \\
\text { Consultant }\end{array}$ & 15 \\
\hline $\begin{array}{l}\text { Design/Engineering } \\
\text { Consultancy }\end{array}$ & $\begin{array}{l}\text { Technical Director } \\
\text { (Innovation) }\end{array}$ & 25 \\
\hline $\begin{array}{l}\text { Design/Engineering } \\
\text { Consultancy }\end{array}$ & $\begin{array}{l}\text { Research Innovation } \\
\text { Manager }\end{array}$ & 17 \\
\hline $\begin{array}{l}\text { Design/Engineering } \\
\text { Consultancy }\end{array}$ & $\begin{array}{l}\text { Collaboration } \\
\text { Consultant }\end{array}$ & 19 \\
\hline $\begin{array}{l}\text { Contractor } \\
\text { Consultancy }\end{array}$ & $\begin{array}{l}\text { Analyst-Project } \\
\text { Collaboration }\end{array}$ & 12 \\
\hline $\begin{array}{l}\text { Contractor } \\
\text { Consultancy }\end{array}$ & $\begin{array}{l}\text { Collaborative } \\
\text { Working Manager }\end{array}$ & 10 \\
\hline Contractor & $\begin{array}{l}\text { Virtual Prototyping } \\
\text { Manager }\end{array}$ & 17 \\
\hline Contractor & $\begin{array}{l}\text { Director } \\
\text { Innovation }\end{array}$ & 35 \\
\hline
\end{tabular}

During the interviews the discussions were focused on the validation of the scenarios. The following key areas were discussed: 
- Feasibility of the scenarios

- Possible drivers/barriers

- Possible implementation projects

- Requirements for the implementation of these scenarios within possible projects.

\section{1) Expert feedback on Scenarios}

During the presentation of the scenarios, experts were asked to give feedback on the components of the scenarios and the steps of implementation. This section summarizes the information gathered for each scenario of mobile technology implementation in construction projects during the validation meetings.

The validation meetings revealed that the briefing stage for any technology implementation rarely happens in the construction industry. This is one of the most important bottlenecks of technology implementation into construction processes. There is no a shared vision and structured strategy for the implementation of technologies in resulting in communication and data storage problems during projects. The current use of mobile technologies is achieving limited benefits due the lack of integration between systems and users, having a shared vision for the planning and implementation of these technologies is key to achieving the full benefits of mobile collaborative environments. Another aspect that may facilitate the implementation of mobile technologies is to make these parts of the contractual arrangements. In general contract documentations include closes such as "project leaders provide adequate IT to satisfy delivery of project”. These do not mention specific technologies for the different processes; however some of these are introduced late in projects not allowing adequate time for their implementation leading to problems with use and coordination between project members. The following sections present a summary of various scenario-inhibitors and findings identified during the meetings.

\section{Lack of Automation:}

It was highlighted that Mobile 2D/3D and 4D Collaboration scenarios assume very high level of automated processes which does not fully exist in the construction industry at the moment. An illustrative comment for Mobile 2D/3D scenario was, "Technology and process exist in some projects but not used in a way that achieves full benefits". A similar comment for 4D Collaboration scenario was, "Collaboration process does not exist for 4D scenario in the industry, on the other hand, modelling technology is continuously improved to converge 4D models with project extranets". It was mentioned that there are very few projects using 4D modelling and limited real-time $4 \mathrm{D}$ solutions for the collaboration of supply chain in the construction industry.

\section{Interoperability:}

Interoperability issues were identified as a major barrier for the design information exchange and 4D collaboration. An illustrative comment on design information exchange was, "Designers might have difficulties due to limited printing facilities in PDF format, and therefore, mobile 2D/3D collaboration should support model files in various CAD (computer aided design) formats". One way forward is to make designers and other project participants use IFC (Industry Foundation Class) based 4D modeling and collaboration products. Before having such products in the market, a short term solution could be grouping contractors and designers using contractual agreements so that they can exchange design information and collaborate 4D models on common platforms for better design-construction collaboration.

\section{Mobile Communication and Wireless Networking:}

Various mobile communication and wireless networking limitations were identified as inhibitors to the uptake of the concepts presented in the scenarios.

- Limited display size and usability of the mobile devices were identified as major limitations by many experts. As site users are not usually technically literate, applications and devices will be the key factors in determining the success of implementation.

- Most construction sites are not equipped with wireless networks and contractors are not aware of the various existing technologies and how to deploy these technologies on site.

- Deploying wireless local area networks on site takes nearly four to six weeks due to the time required for landline and ADSL installation. Therefore, networks and installation should be planned before site mobilization.

- It was highlighted that wireless bandwidth is a factor limiting the use of bandwidth intensive applications. Therefore, applications running on mobile devices and wireless networks should be designed according to the network capability and requirements. An example comment on network speed was, "Speed of access is the most important aspect which directly affect the rate of use and adoption of Mobile 2D/3D and 4D Collaboration scenarios”.

\section{Security and Trust:}

Industry experts highlighted some security and trust issues which can possibly affect the realisation of some of the concepts presented in the scenarios.

- Security is an important key factor for the success of Mobile 2D/3D and 4D Collaboration scenarios due to using on site wireless networks and internet backbone for confidential data transfer.

- As most of the corporate data is confidential, contractors and sub-contractors may not like to provide free access to their private project information. Therefore, project information needs to be identified and filtered before it can be used in scenarios similar to those presented in the research.

\section{Cultural Issues:}

It was revealed during the interviews that many cultural issues specific to the construction industry can be barrier to the implementation of the scenarios in the live construction projects. An illustrative comment was, "People do not want to change the way they work on site and embrace the use of ICT on projects due to the fear that these systems might not working properly and could cost huge amount of investment”. Possible solutions to these cultural barriers could be: to educate users that using such technologies can facilitate collaboration; and to demonstrate to the project teams how they can reduce project costs and better manage risk.

\section{Business Model Issues:}

Creating the business models for the realisation of these scenarios is a critical step for the implementation of 
mobile and wireless technologies. Telecom operators, technology vendors, software developers and construction based organisations need to work collaboratively to implement these technologies into site processes and to develop efficient business models. An illustrative comment on creating business model was, "3G scenario is ideal for emergency planning, instantaneous decision making, capturing photo and video at construction site and sharing visual information with the project team." However, there is resistance due to high pricing strategy of telecom operators and lack of coverage at remote construction sites. There is a need for the new strategies and packages developed by operators in order to adapt 3G technology to construction business.

\section{CONCLUSION}

Visualisation through mobile technologies is an important research topic. Due to the limitation in computational resources of mobile devices, visualisation of design documents through mobiles has not been investigated in detail. However, integrating mobile devices into the visual representation of design documents and specifications may offer new opportunities for accessing and monitoring the construction site remotely. Mobile visualisation and 3G visual communication may change the collaboration practices between the project stakeholders during the execution of the construction activities.

This paper presented the implementation scenarios based on the results of a detailed industry survey after literature and technology reviews. The implementation scenarios within the research were validated with experts from contractors, design/engineering consultancy and management consultancy organizations. The Scenario validation interviews were carried out to identify technical and non-technical barriers standing on the way of implementing mobile visualisation on site. As a result of these meetings, some organizations accepted to support and evaluate the research within one of their construction projects. Future research will focus on the technology setup and evaluation of mobile visualisation implementation within these live construction projects.

\section{REFERENCES}

[1] S. Emmitt, and C. Gorse, "Construction Communication", Blackwell Publishing, 2003.

[2] M.E.L. Hoezen, I.M.M.J Reymen, and G.P.M.R. Dewulf, "The Problem of Communication in Construction.” International Conference on Adaptable Building Structures, Netherlands, 03-05 July 2006.
[3] A. Griffith, and A.C. Sidwell, "Constructability in Building and Engineering Projects”, MacMillan Building and Surveying Series, (1995).

[4] F.E. Gould, and N.E. Joyce, "Construction Project Management", Prentice Hall, 2000

[5] R.H. Clarke, "Site Supervision”, Thomas Telford Ltd, 1988.

[6] I. Ferguson, "Buildability in Practice", Mitchell Publishing Company Ltd, 1989.

[7] M. Sarshar, "Construction Integration: Vision and Barriers." Designing, Managing and Supporting Construction Projects Through Innovation and IT Solutions, Conference, 18-21 February 2004, Langkawi, MALAYSIA.

[8] V.R. Kamat, and J.C. Martinez, "Automated Generation of Dynamic-Operations Level Virtual Construction.”, ITcon, Vol.8, 2003, pp.65-83.

[9] H. J. Wang, J.P. Zhang, K.W., Chau, M. Anson, “4D Dynamic management for Construction planning and resource utilization”, Automation in Construction, 13, 2004, 575-589. doi:10.1016/j.autcon.2004.04.003

[10] R. Best, and G. De Valence, "Design and Construction”, Elsevier Science Ltd, 2002.

[11] K. McKinney, and M. Fischer, "Generating, evaluating and visualizing construction schedules with CAD tools”, Automation in Construction, 7, 1998 p.433-447. doi:10.1016/S09265805(98)00053-3

[12] G. Forster, "Construction Site Studies", Longman Scientific\& Technical, 1989.

[13] P. Wilkinson, "Construction Collaboration Technologies-The extraet evolution”, Taylor \& Francis Group, 2005.

[14] A. Griffith, P. Stephenson, and P. Watson, "Management Systems for Construction”, Pearson Education Limited Inc., 2000.

[15] Construction Productivity Network, (CPN) report of a workshop, Durham, 2006.

[16] Mobile Enterprise Analyst, "Construction: Can the sleeping giant be roused?” (http://www.comitproject.org.uk/downloads/news/M EAStent.pdf), Accessed July 2006.

[17] G. Ringland, "Scenarios in Business”, John Wiley \& Sons, 2002.

\section{AUTHORS}

Ozan Koseoglu completed his $\mathrm{PhD}$ in Loughborough University, Civil \&Building Engineering Department and he is currently working for Laing Rourke, UK (e-mail: okoseoglu@laingorourke.com).

Dino Bouchlaghem is Professor of Architectural Engineering at Civil \& Building Engineering, Loughborough University and the Director of Centre for Innovative Construction Engineering at Loughborough University (n.m.bouchlaghem@lboro.ac.uk).

Manuscript received 3 July 2008. Published as submitted by the authors. 